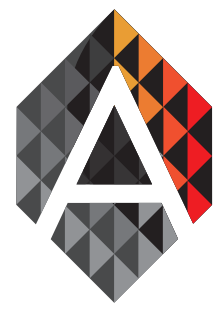

ADCAIJ: Advances in Distributed Computing and Artificial Intelligence Journal Regular Issue, Vol. 7 N. 4 (2018), 35-44

eISSN: $2255-2863$

DOI: http://dx.doi.org/10.14201/ADCAIJ2018743544

\title{
Simulating Evacuation Crowd with Emotion and Personality
}

\author{
Carlos Juaréz, Cristian Maizanche, Raul Matilla, \\ and Sergio Mellídez
}

toranzocj@usal.es santiago.93@hotmail.es r.matilla@usal.es sergiomellidezacosta@usal.es University of Salamanca

$\begin{array}{ll}\text { KEYWORD } & \text { ABSTRACT } \\ \begin{array}{l}\text { emergencies; } \\ \text { emotion } \\ \text { contagion; }\end{array} & \begin{array}{l}\text { Crowd evacuation has attracted great attention, the number of emergencies continues } \\ \text { security; behavior incere Thanks to the technology, it is possible to deduce the behavior of the crowd } \\ \text { in emergencies, improving security. The multitude enters into a state of panic, so it is } \\ \text { necessary to have action protocols for these situations. This work tries to establish a } \\ \text { multi-agent model of emotional contagion that simulates the behavior of the crowd in } \\ \text { an evacuation. The method is proposed for closed areas such as supermarkets, stadi- } \\ \text { ums, soccer, stadiums, etc. The emotional contagion will accelerate the evacuation, } \\ \text { but the congestion will occur if the panic emotion is spread too fast. }\end{array}\end{array}$

\section{Introduction}

We intend to achieve a multi-agent model in which we try to simulate the sensation and emotions in emergency situations, such as an incentive. To do this we must take into account how the subjects involved in these situations behave. As all people are not equally reluctant in the face of danger, we have analyzed the different behaviors of the subjects and have reflected this in our project. In order to capture this idea we have developed a software in which we make use of these analysis studied using agents.

We use agents as an abstraction mechanism, so that it can be implemented without a corresponding software structure. It is designed so that the subjects are represented by several agents that interact with each other to simulate the evacuation correctly. Fire is also an agent that extends progressively and indicates its position to the controlling agent.

The multi-agent system used is suitable for this solution since there are multiple resolution methods and multiple subjects that work together in order to avoid burning and find the output within the simulation.

Nowadays, where society prefers to live in urban areas and tends to concentrate more and more in large cities, it is normal to find events or places where a large number of people can meet, to guarantee the safety of all in these situations it is necessary to have security protocols and evacuation in any type of emergency such as natural disasters, earthquakes or fires, that guarantee to be able to face these situations in a safe and efficient way. The losses caused by emergencies can be greatly reduced and the efficiency of emergency decision-making can be improved.

Carlos Juaréz, Cristian Maizanche, Raul Matilla, and Sergio Mellídez

Simulating Evacuation Crowd with Emotion and Personality
ADCAIJ: Advances in Distributed Computing and Artificial Intelligence Journal Regular Issue, Vol. 7 N. 4 (2018), 35-44 elSSN: 2255-2863 - http://adcaij.usal.es Ediciones Universidad de Salamanca - CC BY NC DC 
To design these protocols, it is important to know the behavior of people in dangerous situations and how the feelings and emotions of these people are transmitted between them and affect the evacuation. Normally, existing crowd models treat people as a "particle". Regardless of psychological and emotional factors, it is difficult to accurately describe the behavioral characteristics of the crowd in emergency situations. The behavior of people will be affected by the environment and will influence the evacuation procedures. Understanding the psychological behavior of the crowd is crucial for the effective management of emergencies. Therefore, this article will take into account the personality and emotion and analyze the evacuation behavior of the crowd in a confined space fire.

\section{Related work}

In recent years, thanks to the continuous development of technology, it has become possible to simulate social phenomena. This phenomenon has become a new interdisciplinary field. With new technologies, social computing provides a way to study complex social systems. It can be used to analyze various behaviors in human society.

The following is a list of some of the authors who deal with this topic:

- Qui et al., (2011) proposed a framework for a "scenario-response" emergency management platform. [1,2]

- Liu et al., (2018) proposed a method of psychological simulation of crowds based on psychological research. [3]

- Zheng (2009) proposed a crowd evaluation simulation model. [4]

- Chen X et al (2009) simulated public panic based on computational experiments. Based on the psychological threshold model. [5]

- Shen proposed a dynamic model of crowd behavior under crisis events. [6]

- Sun DY (2007) used foreground theory to describe the decisions of the individual's behavior and established a model of perception of the fear of disasters. He believes that people's behavior decisions in emergencies are based on limited information. People will assess the situation first and then make decisions based on changes in the situation. [7]

It is important that, in crowd assessment simulation, behaviors are credible. In virtual reality, crowd animation is important.

- Kapadia et al (2011) developed a multi-agent simulation framework that can analyze both flexible behavioral descriptions and autonomous behavioral generation. In this virtual environment it is possible to control many details of the agents. [8]

- Beltaief et al (2011) proposed a multi-agent simulation model. The experiments verified that it can realistically simulate late human behavior based on psychological findings. [9]

- Park et al (2013) proposed a model of behavior to avoid collisions and to analyze several possible paths from the perspective of psychology. It could provide a theoretical basis.[10]

- Wagner et al (2014) proposed an emergency decision system to simulate the evacuation of the concert hall crowd in the presence of a fire disaster. [11]

- Joo et al (2013) studied crowd evacuation behavior in emergencies, presented a general framework, and designed an algorithm for agent evacuation behavior based on affordability. Fire evacuation is simulated in experiments. [12]

- Song et al (2013) proposed a framework and key technologies for exhaust simulation to support efficient emergency evacuation in bioterrorism scenarios. [13]

- Mao et al (2012) proposed a probabilistic inference method that could analyze agent behavior from aspects of objectives, events, and states, and consider the agent's willingness in group decision-making. [14]

- Manzoor et al (2013) analyzed the role of emotion regulation in socially affected decision making from three aspects: regulation of feelings, affective infection, and evaluation of feelings. The study focused on the regulation of the emotions of the agents and could help to design the intelligent decision-making system of the environment. [15]

Carlos Juaréz, Cristian Maizanche, Raul Matilla, and Sergio Mellídez

Simulating Evacuation Crowd with Emotion and Personality
ADCAIJ: Advances in Distributed Computing and Artificial Intelligence Journal Regular Issue, Vol. 7 N. 4 (2018), 35-44 elSSN: 2255-2863 - http://adcaij.usal.es Ediciones Universidad de Salamanca - CC BY NC DC 
Table 1: project reviewed

\begin{tabular}{|l|l|}
\hline Artículo & Característica más importante \\
\hline Kapadia et al (2011) & Developed a multi-agent simulation framework \\
\hline Beltaief et al (2011) & Proposed a multi-agent simulation model \\
\hline Park et al (2013) & roposed a model of behavior to avoid collisions and to analyze several possible paths \\
\hline Wagner et al (2014) & proposed an emergency decision system \\
\hline Song et al (2013) & $\begin{array}{l}\text { proposed a framework and key technologies for exhaust simulation to support efficient } \\
\text { emergency evacuation }\end{array}$ \\
\hline
\end{tabular}

\section{The proposed model}

In our multi-agent model, we can find people with feelings and emotions, mainly we will take into account the level of stress of the people and how it spreads among them. We also identify dangers or uncertainties, in this case the fire will be the main one that is going to increase with the passage of time and spread at a speed $x$ through a room (imaginary board in which our agents will meet). The level of stress of the people will increase with the passage of time. However, the level of stress will decrease the further away they are from the fire and the closer to an emergency exit. Depending on the level of stress they will move more quickly and skillfully through the room, and if they reach a maximum level of stress they will go into shock and remain still for a few seconds or until someone else helps them. If people get burned by the fire, they will scream and may even die, causing the stress of the rest of the people inside to increase.

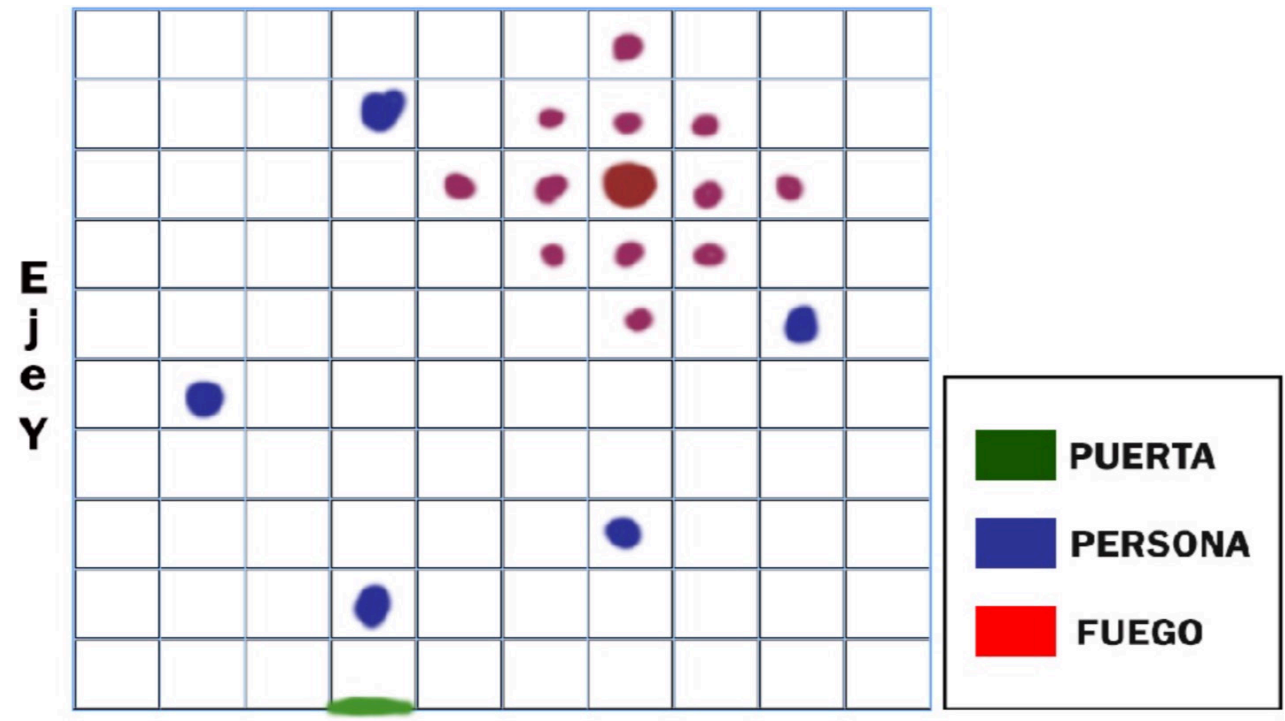

Eje X

[Figure 1: example fire simulation in position $(9,3)$ ]

In this picture, describe the scenario where the evacuation occurs. To develop the model we will use a broadcast architecture for the passage of messages, where we will send the $x$ and $y$ coordinates of the person's current position, the $x$ and $y$ position of the door to which the person is going, the next position $(x, y)$, the speed

Carlos Juaréz, Cristian Maizanche, Raul Matilla, and Sergio Mellídez

Simulating Evacuation Crowd with Emotion and Personality
ADCAIJ: Advances in Distributed Computing and Artificial Intelligence Journal Regular Issue, Vol. 7 N. 4 (2018), 35-44 elSSN: 2255-2863 - http://adcaij.usal.es Ediciones Universidad de Salamanca - CC BY NC DC 
at which the person moves, and the state of the person (shock, helping, burning, normal), the level of stress, proximity to the fire. Figure 2 shows what the communication between the agents would look like:

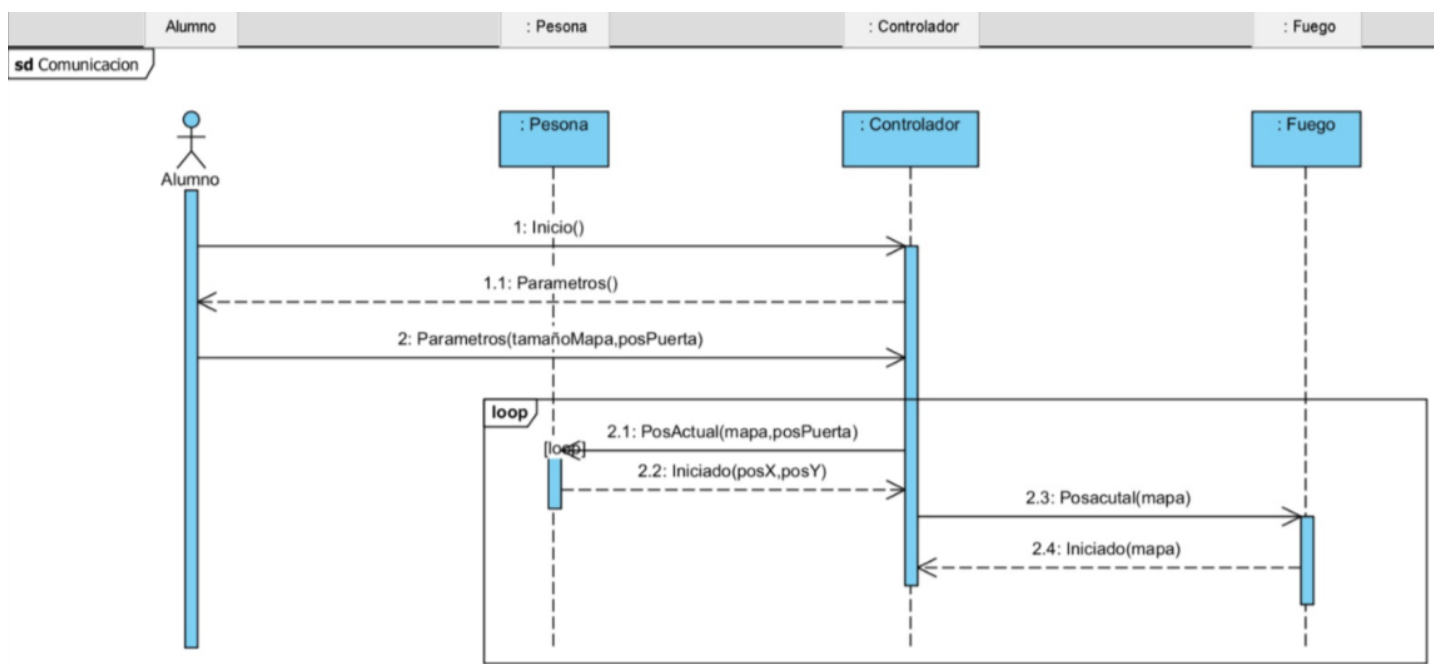

[Figure 2: sequence diagram]

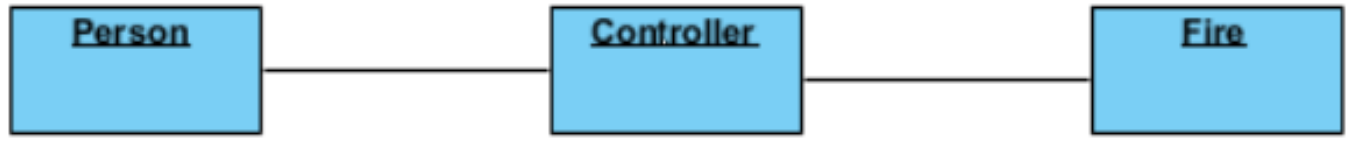

[Figure 3: objects diagram]

Carlos Juaréz, Cristian Maizanche, Raul Matilla, and Sergio Mellídez

Simulating Evacuation Crowd with Emotion and Personality
ADCAIJ: Advances in Distributed Computing and Artificial Intelligence Journal Regular Issue, Vol. 7 N. 4 (2018), 35-44 eISSN: 2255-2863 - http://adcaij.usal.es Ediciones Universidad de Salamanca - CC BY NC DC 


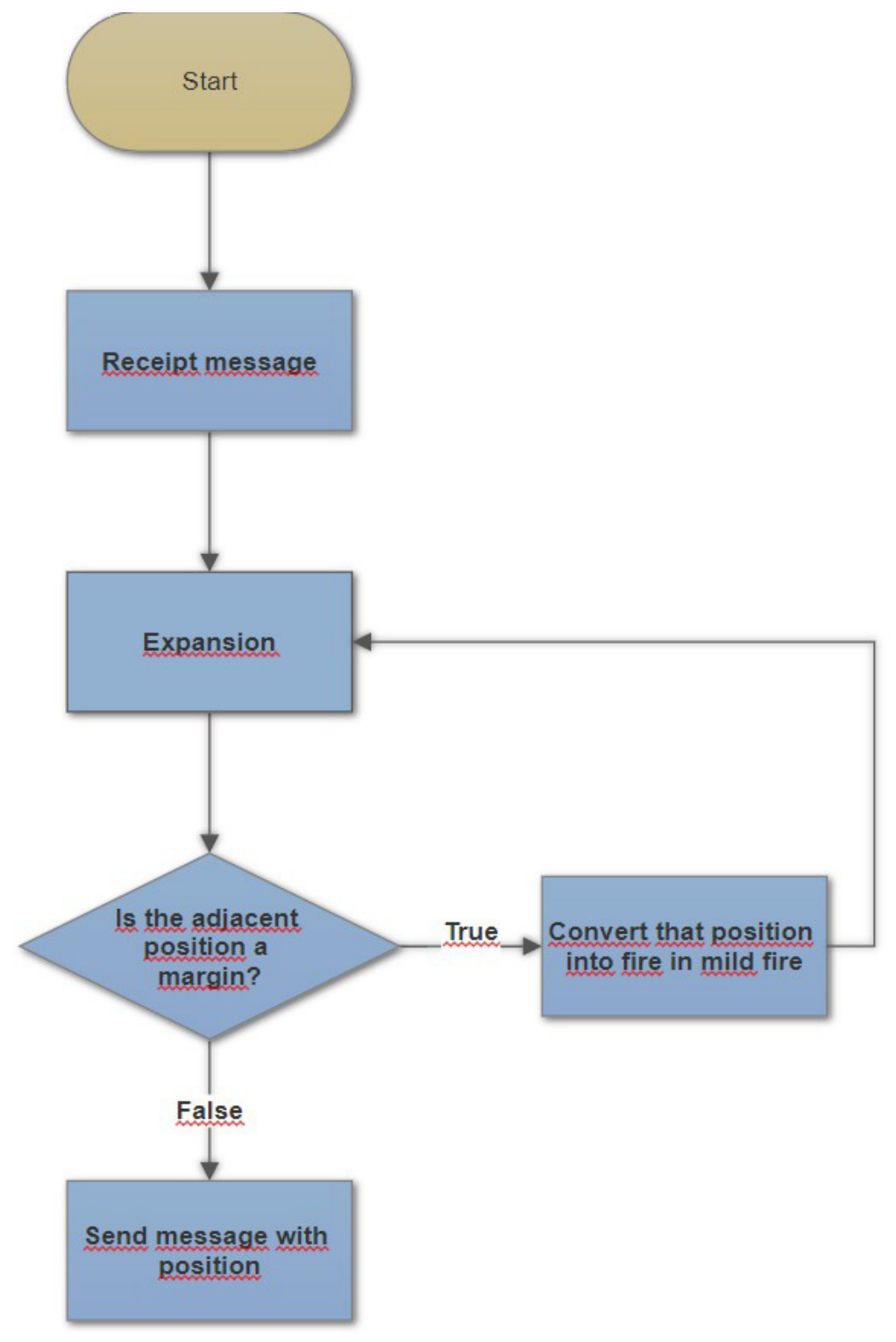

[Figure 4: state diagram of fire]

Carlos Juaréz, Cristian Maizanche, Raul Matilla, and Sergio Mellídez

Simulating Evacuation Crowd with Emotion and Personality
ADCAIJ: Advances in Distributed Computing and Artificial Intelligence Journal Regular Issue, Vol. 7 N. 4 (2018), 35-44 elSSN: 2255-2863 - http://adcaij.usal.es Ediciones Universidad de Salamanca - CC BY NC DC 


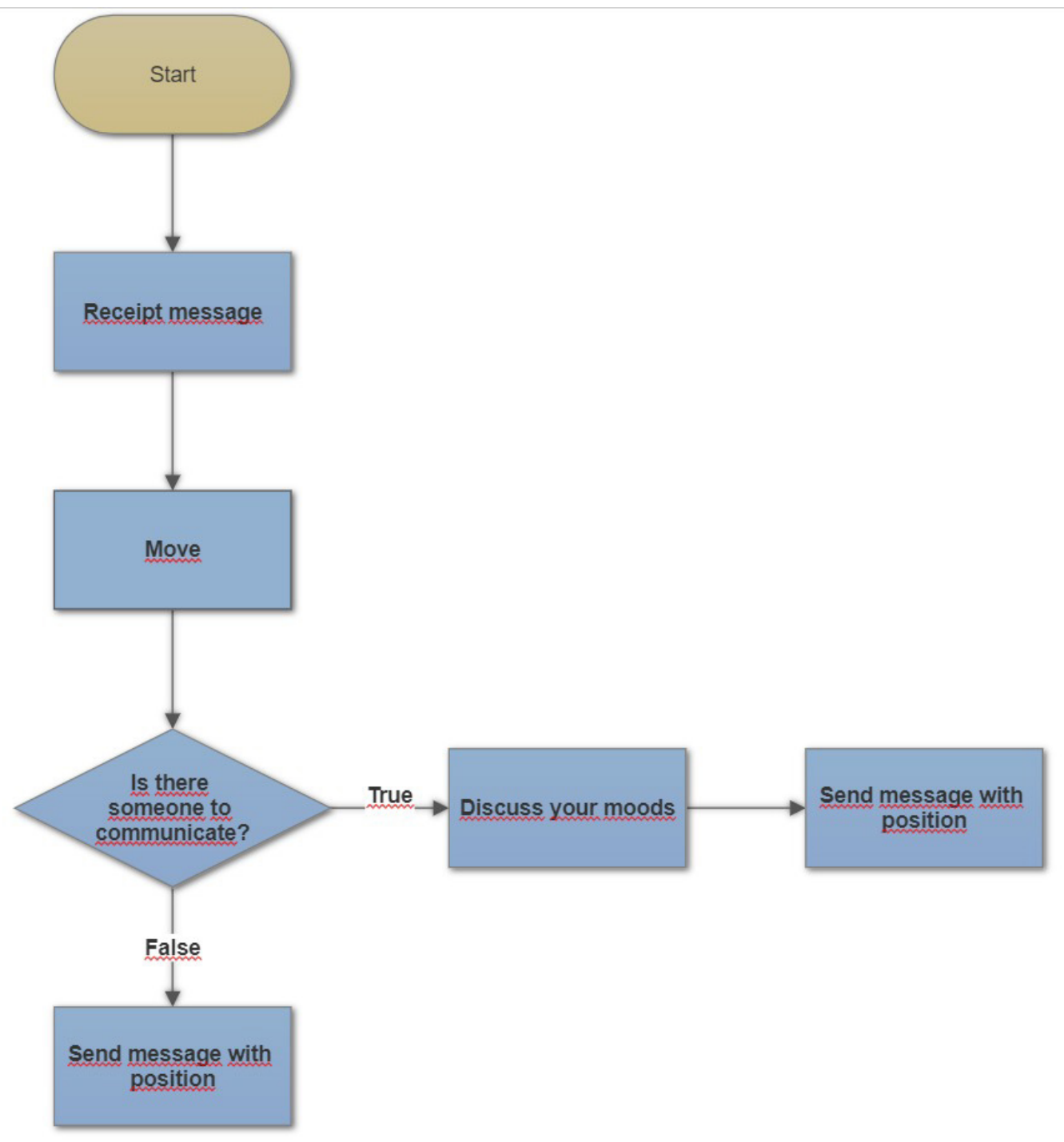

[Figure 5: state diagram of people]

\section{Results}

We have pooled our results from our theoretical and practical analyses and have come to the conclusion that, in emergency situations, people are less likely to act correctly when under a very high level of stress. The following images depict the execution of the program. They illustrate the evolution of the agents in a fire situation. The level of stress increases depending on the location of the agents, lessening their chances of survival.

Carlos Juaréz, Cristian Maizanche, Raul Matilla, and Sergio Mellídez

Simulating Evacuation Crowd with Emotion and Personality
ADCAIJ: Advances in Distributed Computing and Artificial Intelligence Journal Regular Issue, Vol. 7 N. 4 (2018), 35-44 eISSN: 2255-2863 - http://adcaij.usal.es Ediciones Universidad de Salamanca - CC BY NC DC 


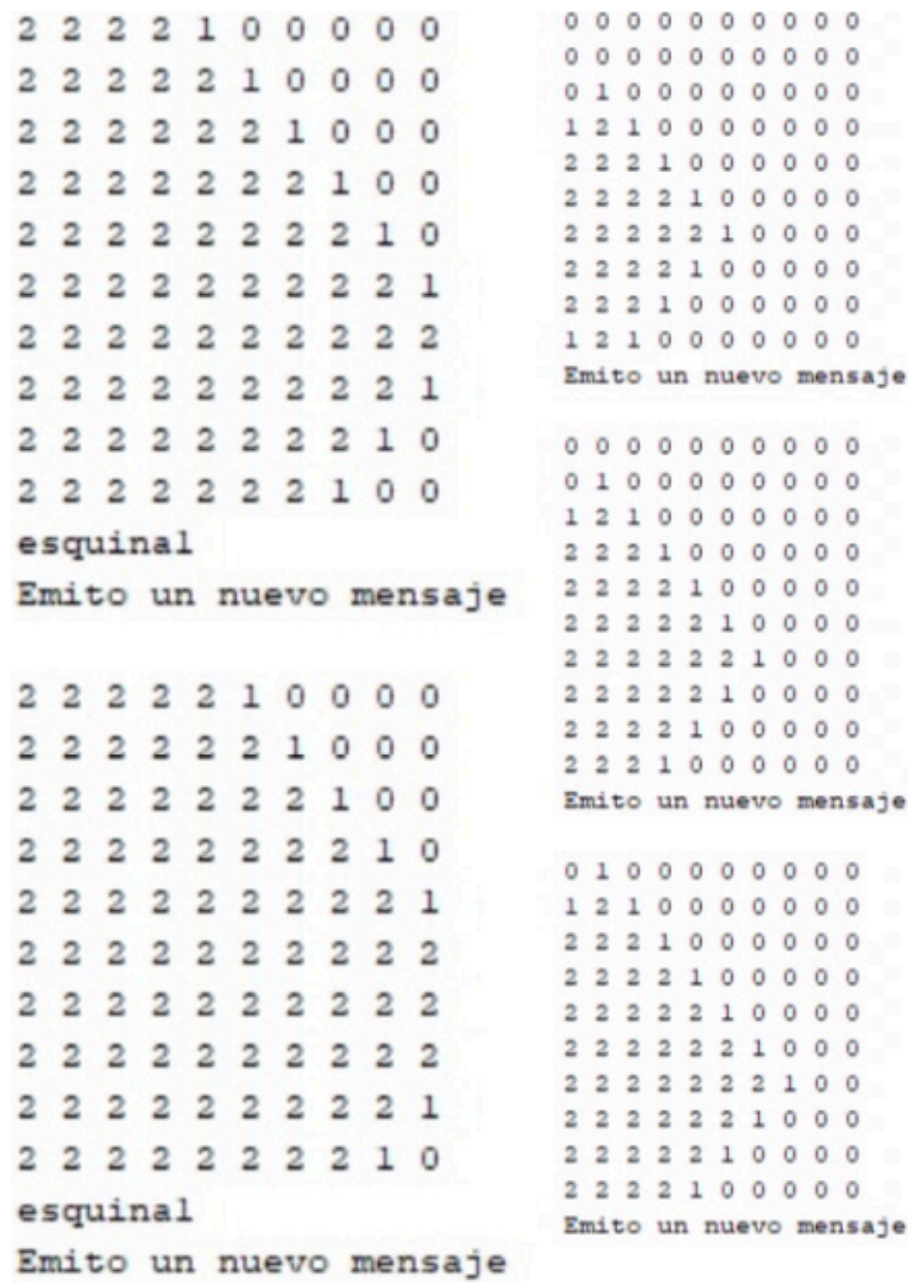

[Figure 6: example of simulation with numbers] 


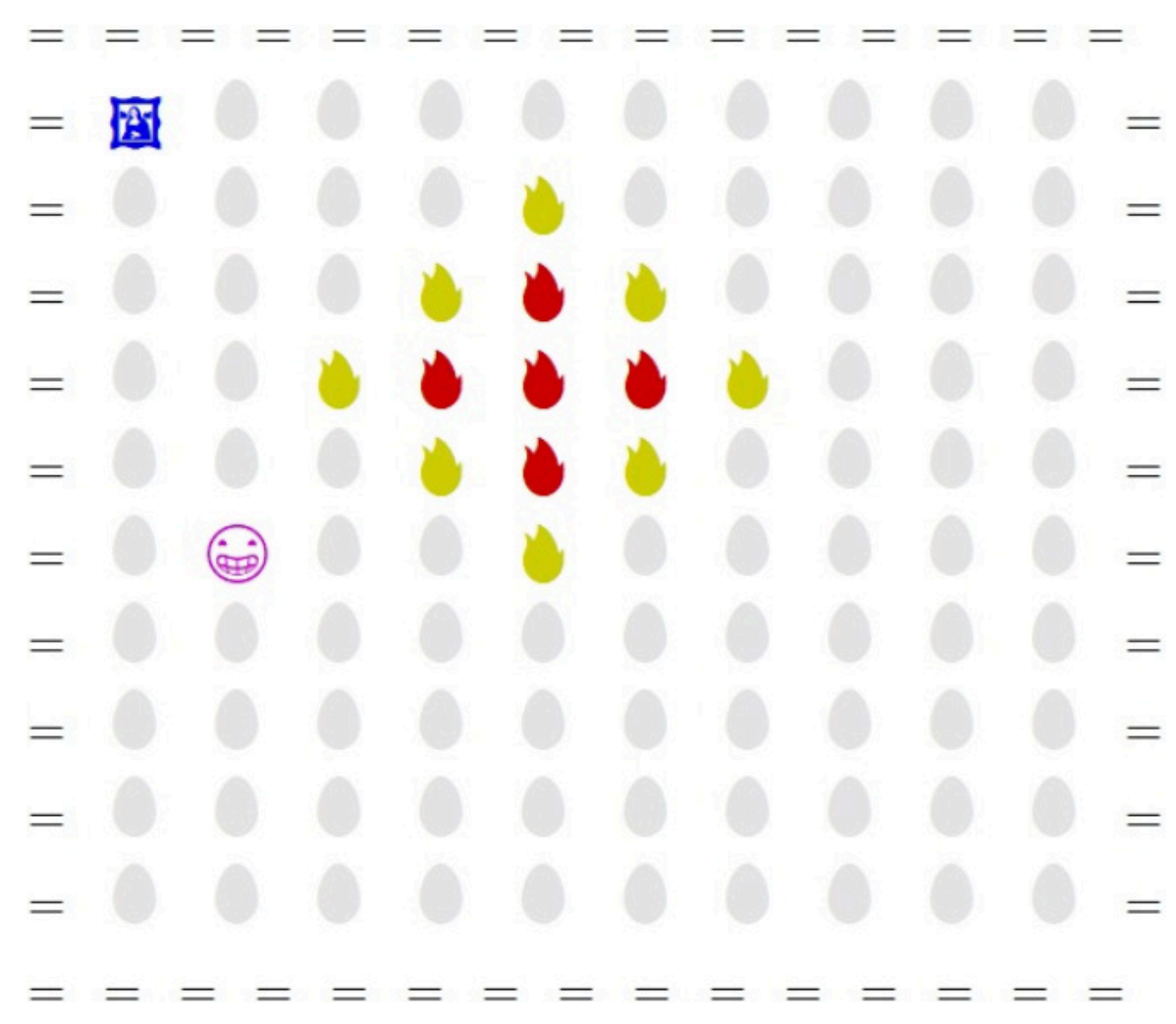

[Figure 6: example of simulation with numbers]

In our application we have used number to simulate the different elements that appear during our simulation as shown in figure 6 in each time that appears a 0 wants to represent that is an empty place to which you can move the person who appears represented by the number the number 3 and the exit with the number 9 but can not be seen in figure 6 . Because the strong fire represented by the number 2 and the weak fire represented by the number 1 have occupied the positions that corresponded to them.

However, in figure 7 we opted for a more graphical representation in which you can clearly see what each icon represents except for the output which is the strangest of all and is represented by a blue box because it is a strange character that attracts attention and for the weak fire we have chosen to put it yellow while stronger by a red color the white space represent them with a figure of a white egg not to squander the image. Although we had to reject this last option because the output by the terminal did not allow us to represent these characters allow us to represent these characters

\section{Conclusions}

With the new technologies you can make an animated simulation in which you can see the visual effects. In this work we try to study the behavior and the emotional contagion of the public in emergency situations. We will study the route that the crowd makes in the inside of a closed space, the behaviors of people are simulated according to their emotions.

In our applications we have tried to emphasize people's feelings as well as to maintain the greatest possible realism in people's behaviour as well as fire without paying too much attention to the environment in which the simulation takes place since we always do it in square rooms of different sizes.

We opted for the use of agents so that each person can act for themselves with a behavior completely independent of the rest and make their own decisions which caused great difficulties when implementing the 
process. On the other hand, the fire also behaves like an agent that is expanding until it ends up occupying the whole room for which we thought it was a good idea to have two different representations on the one hand the weakest fire and on the other hand the strongest fire that is placed after having produced a weak fire in that position.

\section{References}

1. Qiu XG, Fan ZC, Chen B, Cao ZD, Wang FY (2011) Requirements and challenges of modeling and simulation in the unconventional emergency management. Syst Simul Technol 3(3):169-176.

2. Duan W, Cao ZD, Qiu XG, Wang FY, Zeng DJ (2012) Semantic modeling for artificial society in parallel emergency management system. Syst Eng Theory Pract 32(5):1010-1017.

3. Liao DS, Hou BN, Wang B, Guo Q, Guo J (2011) Crowd psychology simulation incorporating psychometrics and intervention of relationship spaces. J Natl Univ Def Technol 33(3):151-156.

4. Zheng XP, Zhong TK, Liu MT (2009) Study on numeral simulation approaches of crowd evacuation. J Syst Simul 21(12):3503-3508.

5. Chen X, Fei Q, Li W (2009) A preliminary research on urban mass panic based on computationa-methods for experiment. J Huazhong Univ Sci Technol (Soc Sci Ed) 23(2):34-37.

6. Li F, Shen HZ, Liu SL, Zhang C (2011) The analysis of group behavior dynamics in crisis based on psychological threshold model. J Syst Manag 20(5):513-519.

7. Sun DY (2007) Public emergency and behavioral decision-making. Social Sciences Academic Press (China), Beijing.

8. Kapadia M, Singh S, Reinman G, Faloutsos P (2011) A behavior-authoring framework for multiactor simulations. IEEE Comput Graph Appl 31(6):45-55.

9. Beltaief O, Hadouaj SE, Ghedira K (2011) Multi-agent simulation model of pedestrians crowd based on psychological theories. In: Proceedings of the 4th international conference on logistics (LOGISTIQUA), IEEE, pp 150-156.

10. Park JH, Rojas FA, Yang HS (2013) A collision avoidance behavior model for crowd simulation based on psychological findings. Comput Anim Virtual Worlds 24:173-183.

11. Wagner N, Agrawal V (2014) An agent-based simulation system for concert venue crowd evacuation modeling in the presence of a fire disaster. Expert Syst Appl 41:2807-2815.

12. Joo J, Kim N, Wysk RA, Rothrock L, Son YJ, Oh YG, Lee S (2013) Agent-based simulation of affordance-based human behaviors in emergency evacuation. Simul Model Pract Theory 32:99-115.

13. Song YQ, Gong JH, Li Y, Cui TJ, Fang LQ, Cao WC (2013) Crowd evacuation simulation for bioterrorism in micro-spatial environments based on virtual geographic environments. Saf Sci 53:105-113.

14. Mao WJ, Gratch J, Li XC (2012) Probabilistic plan inference for group behavior prediction. IEEE Intell Syst 27(4):27-36.

15. Manzoor A, Treur J (2013) Modelling the role of emotion regula- tion and contagion in socially affected decision making. Proc Soc Behav Sci 97:73-82.

Carlos Juaréz, Cristian Maizanche, Raul Matilla, and Sergio Mellídez

Simulating Evacuation Crowd with Emotion and Personality
ADCAIJ: Advances in Distributed Computing and Artificial Intelligence Journal Regular Issue, Vol. 7 N. 4 (2018), 35-44 elSSN: 2255-2863 - http://adcaij.usal.es Ediciones Universidad de Salamanca - CC BY NC DC 
